\title{
De NVMO-cursussen in 2003
}

De Commissie Professionalisering Docenten (CPD) coördineert een van de beleidsprioriteiten van de NVMO, te weten de onderwijskundige professionalisering van docenten bij medische opleidingen. De CPD beveelt $\mathrm{u}$ de volgende NVMO-cursussen van harte aan:

\section{Professioneel gedrag}

Deze nieuwe en zeer actuele cursus is bedoeld voor al degenen die te maken hebben met professioneel gedrag bij het geven, coördineren of ontwikkelen van onderwijs in de geneeskunde / gezondheidszorg. Na het volgen van deze cursus is men in staat het professioneel gedrag van de individuele student systematisch te beoordelen, daarover met betrokkene tot een vruchtbaar gesprek te komen en - indien nodig - een traject voor gedragsverandering te ontwikkelen.

\section{Datum en plaats}

11 maart 2003 in Maastricht en 28 maart 2003 in Nijmegen.

\section{Docenten}

Dr. K.P.M. van Spaendonck, psycholoog, UHD communicatieve vaardigheden en ontwikkeling van professioneel gedrag, UMC St. Radboud, Nijmegen (cursuscoördinator),

Dr. S.J. van Luijk, studieadviseur, Faculteit der Geneeskunde, Universiteit Maastricht.

\section{Kosten}

De kosten van deze tweedaagse cursus bedragen $€ 500$.

\section{Organiseren van Portfolio-leren}

Deze cursus is bedoeld voor klinische docenten en onderwijscoördinatoren, die het leren werken met behulp van een portfolio willen introduceren of hebben geïntroduceerd. Na het volgen van deze cursus is de deelnemer in staat een compleet portfoliosysteem, onder andere inclusief beoordelingssysteem en organisatieplanning, voor de eigen onderwijssituatie te ontwerpen.

\section{Datum en plaats}

16 en 23 mei 2003 in Utrecht.

\section{Docenten}

Prof. dr. H.J.M. van Rossum, hoogleraar Medisch Onderwijs, Onderwijsinstituut VU Medisch Centrum te Amsterdam (cursuscoördinator).

Prof. dr. J.P.M. Denekens, hoogleraar Huisartsgeneeskunde, Centrum voor Huisartsgeneeskunde, Universiteit Antwerpen.

\section{Kosten}

De kosten van deze tweedaagse cursus bedragen $€ 500$. 


\section{Curriculumontwikkeling voor het medisch onderwijs}

Deze cursus is bedoeld voor docenten en andere personen op beleids-, bestuurs- en commissieniveau, die betrokken zijn bij curriculumontwikkeling in het medisch onderwijs of een medische opleiding of dat in de nabije toekomst zullen zijn. De cursus beoogt de cursisten instrumenten aan te reiken en te laten ontdekken waarmee het proces van herprogrammering van medisch - of verwant - onderwijs doelgericht en effectief kan verlopen.

\section{Datum en plaats}

25 en 26 juni 2003 in Driebergen.

\section{Docenten}

Prof. dr. Th.J. ten Cate, hoogleraar Medisch Onderwijskunde, Universitair Medisch Centrum Utrecht (cursuscoördinator) en enkele gastdocenten.

\section{Kosten}

De kosten van deze tweedaagse cursus bedragen $€ 650$, inclusief overnachtingskosten op 25 juni.

\section{Toetsing van medische competentie}

Deze cursus is bedoeld voor degenen die onderwijs geven, coördineren of ontwikkelen en in dat kader te maken hebben met toetsing van medische competentie. De cursus beoogt de deelnemers inzicht te geven in: functies van toetsing, methoden van toetsing, samenstellen van toetsen, programmeren en organiseren van toetsen, onderwijskundige waarde van toetsing, de haalbaarheid van toetsing en tot slot psychometrische begrippen.

\section{Datum en plaats}

10 oktober 2003 in Utrecht en 23 en 24 oktober 2003 in Woudschoten.

\section{Docenten}

Prof. dr. C.P.M. van der Vleuten, psycholoog, hoogleraar Onderwijskunde en voorzitter van de Capaciteitsgroep Onderwijsontwikkeling en Onderwijsresearch van de Faculteit Geneeskunde, Universiteit Maastricht.

Dr. L.W.T. Schuwirth, arts, medewerker van de Capaciteitsgroep Onderwijsontwikkeling en Onderwijsresearch, Faculteit Geneeskunde, Universiteit Maastricht.

\section{Kosten}

De kosten van deze driedaagse cursus bedragen $€ 900$, inclusief de overnachting op 23 oktober.

\section{Vaardigheidstraining}

Deze cursus is bedoeld voor docenten en organisatoren die betrokken zijn of worden bij vaardigheidsonderwijs in gezondheidszorgopleidingen. Na het volgen van deze cursus is de deelnemer in staat de belangrijkste principes van het vaardigheidsonderwijs toe te passen in de eigen werksituatie.

\section{Datum en plaats}

31 oktober 2003 in Maastricht en 28 november 2003 in Nijmegen.

\section{Docenten}

Dr. J. van Dalen, psycholoog, coördinator onderwijs communicatievaardigheden, Faculteit der Geneeskunde, Universiteit Maastricht (cursuscoördinator).

Drs. L. Fluit, arts/onderwijskundige, stafmedewerker onderwijs geneeskunde, Universitair Medisch Centrum St. Radboud, Nijmegen.

\section{Kosten}

De kosten van deze tweedaagse cursus bedragen $€ 500$. 


\section{Onderzoek van medisch onderwijs}

Deze cursus is bedoeld voor docenten en onderwijskundigen die ervaring willen opdoen in onderzoek van medisch onderwijs, of hun ervaring willen uitbreiden. De cursus beoogt deelnemers in staat te stellen zelfstandig een onderzoek over een medisch onderwijskundig onderwerp op te zetten en uit te voeren. Eerst worden enkele gesimuleerde onderzoeken doorgenomen, waarbij diverse onderzoeksdesigns en onderdelen van onderwijskundig onderzoek de revue passeren. Vervolgens worden de ideeën van de cursisten over hun eigen onderzoeksvoorstel besproken. Het verdere vervolg van de cursus geschiedt aan de hand van eigen onderzoek van de cursisten. Daarbij komt het verzamelen en analyseren van onderzoeksdata aan de orde alsmede de verslaglegging.

\section{Datum en plaats}

13 november 2003 in Egmond aan Zee, 15 januari 2004 en 4 november 2004 in Utrecht.

\section{Docenten}

Prof. dr. A.J.J.A. Scherpbier, arts, wetenschappelijk directeur Onderwijsinstituut, Faculteit der Geneeskunde, Maastricht, (cursuscoördinator).

Dr. ir. A.M.M. Muijtjens, statisticus, Faculteit der Geneeskunde, Maastricht.

\section{Kosten}

De kosten van deze driedaagse cursus zijn $€ 750$ (exclusief de overnachtingskosten in Egmond vóór het NVMO congres).

\section{Co-assistentschappen: onderwijs in de klinische fase}

Deze cursus is bedoeld voor al degenen die betrokken zijn bij de uitvoering en/of de ontwikkeling van het onderwijs in de klinische fase, zowel in de academische ziekenhuizen als in de geaffilieerde ziekenhuizen. De cursus beoogt de deelnemers bewust te maken van het specifieke karakter van het onderwijs in de klinische fase van de opleiding geneeskunde. De cursus richt zich zowel op het specifieke karakter als op de veranderingen die zich momenteel in alle opleidingen geneeskunde voltrekken in deze fase.

\section{Datum en plaats}

19 november 2003 in Egmond aan Zee, voorafgaand aan het NVMO-congres.

\section{Docenten}

Prof. dr. P.M.J. Stuyt, internist, directeur onderwijsinstituut, Universitair Medisch Centrum St. Radboud, Nijmegen (cursuscoördinator).

Dr. J.W. Briët, gynaecoloog en onderwijscoördinator Deventer Ziekenhuis, Faculteit der Medische Wetenschappen, Groningen. Prof. dr. G.G.M. Essed, gynaecoloog, hoogleraar methodiek van klinisch onderwijs, Faculteit der Geneeskunde, Universiteit Maastricht.

\section{Kosten}

De kosten van deze cursus bedragen $€ 300$ (exclusief de overnachtingskosten in Egmond vóór het NVMO congres). 


\section{Effectief doceren}

Deze cursus is bedoeld voor docenten geneeskunde die hun onderwijssessie beter willen structureren en uitvoeren en die feedback willen geven, maar ook ontvangen. In de cursus wordt aandacht besteed aan: het doel van effectief doceren, de structuur van een onderwijssessie, het belang van verbale en non-verbale elementen, enkele regels voor feedback.

\section{Datum en plaats}

19 november in Egmond aan Zee, voorafgaand aan het NVMO-congres.

\section{Docenten}

Dr. J. Cohen-Schotanus, hoofd afdeling onderwijsontwikkeling en kwaliteitszorg,
Onderwijsinstituut, Faculteit der Medische Wetenschappen, Groningen.

Drs. R. Venekamp, Vakgroep Chirurgie, Academisch Ziekenhuis Groningen.

\section{Kosten}

De kosten van deze cursus bedragen $€ 250$ (excl. de overnachtingskosten in Egmond vóór het NVMO-congres).

\section{Informatie}

Voor informatie over deze cursussen en inschrijvingen kunt $\mathrm{u}$ terecht bij: mevrouw L.(Lydia) Boonekamp: tel. 030-2538212; e-mail: 1.boonekamp@med.uu.nl.

Overzicht NVMO-cursusssen 2003

\begin{tabular}{|c|c|c|c|c|}
\hline Cursus & Docenten & Plaats & Datum & Kosten \\
\hline $\begin{array}{l}\text { Professioneel gedrag } \\
\text { tweedaagse cursus }\end{array}$ & $\begin{array}{l}\text { K.P.M. van Spaendonck } \\
\text { S.J. van Luijk }\end{array}$ & $\begin{array}{l}\text { Maastricht } \\
\text { Nijmegen }\end{array}$ & $\begin{array}{l}11-03-2003 \\
28-03-2003\end{array}$ & $€ 500$ \\
\hline $\begin{array}{l}\text { Organiseren van portfolioleren } \\
\text { tweedaagse cursus }\end{array}$ & $\begin{array}{l}\text { H.J.M. van Rossum } \\
\text { J.P.M. Denekens }\end{array}$ & $\begin{array}{l}\text { Utrecht } \\
\text { Utrecht }\end{array}$ & $\begin{array}{l}16-05-2003 \\
23-05-2003\end{array}$ & $€ 500$ \\
\hline $\begin{array}{l}\text { Curriculumontwikkeling } \\
\text { van het medisch onderwijs } \\
\text { tweedaagse cursus }\end{array}$ & $\begin{array}{l}\text { Th.J. ten Cate } \\
\text { Gastdocenten }\end{array}$ & $\begin{array}{l}\text { Driebergen } \\
\text { Driebergen }\end{array}$ & $\begin{array}{l}25-06-2003 \\
26-06-2003\end{array}$ & $€ 650$ \\
\hline $\begin{array}{l}\text { Toetsing van medische } \\
\text { competentie } \\
\text { driedaagse cursus }\end{array}$ & $\begin{array}{l}\text { C.P.M. van der Vleuten } \\
\text { L.W.T. Schuwirth }\end{array}$ & $\begin{array}{l}\text { Utrecht } \\
\text { Woudschoten } \\
\text { Woudschoten }\end{array}$ & $\begin{array}{l}10-10-2003 \\
23-10-2003 \\
24-10-2003\end{array}$ & $€ 900$ \\
\hline $\begin{array}{l}\text { Vaardigheidstraining } \\
\text { tweedaagse cursus }\end{array}$ & $\begin{array}{l}\text { J. van Dalen } \\
\text { L. Fluit }\end{array}$ & $\begin{array}{l}\text { Nijmegen } \\
\text { Maastricht }\end{array}$ & $\begin{array}{l}31-10-2003 \\
28-11-2003\end{array}$ & $€ 500$ \\
\hline $\begin{array}{l}\text { Onderzoek van medisch } \\
\text { onderwijs } \\
\text { driedaagse cursus }\end{array}$ & $\begin{array}{l}\text { A.J.A. Scherpbier } \\
\text { A.M.M. Muijtjens }\end{array}$ & $\begin{array}{l}\text { Egmond aan Zee } \\
\text { Utrecht } \\
\text { Utrecht }\end{array}$ & $\begin{array}{l}13-11-2003 \\
15-01-2004 \\
04-11-2004\end{array}$ & $€ 750$ \\
\hline $\begin{array}{l}\text { Co-assistentschappen: } \\
\text { onderwijs in de klinische fase }\end{array}$ & $\begin{array}{l}\text { P.M.J. Stuyt } \\
\text { J.W. Briët } \\
\text { G.G.M. Essed }\end{array}$ & Egmond aan Zee & $19-11-2003$ & $€ 300$ \\
\hline Effectief doceren & $\begin{array}{l}\text { J. Cohen-Schotanus } \\
\text { R. Venekamp }\end{array}$ & Egmond aan Zee & $19-11-2003$ & $€ 250$ \\
\hline
\end{tabular}

